\title{
Design of Mobile Communication Indoor Distribution System
}

\author{
Jinsheng Mu,Huiling Su,Guang Xu,Jiaxing Jiang \\ Dingtai Communication Construction Engineering Co., Ltd., Shanghai, China
}

\begin{abstract}
With the development of economy, the improvement of people's living standard has been increasing and the construction of buildings is becoming more demanding. These buildings are large in scale and of good quality and have a strong shielding effect on mobile phone signals. In the middle of the large-scale buildings, underground shopping malls, underground parking and other environments, the mobile communication signal is weak hence the phone cannot be used normally and forming a mobile communication blind area and shadow area. In the middle floor, due to the surrounding different base station signal overlap, the ping-pong effect, frequent switching of mobile phones and even dropped calls are seriously affecting the normal use of mobile phones. In the building's higher floors, due to the height of the base station antenna, it has abnormal coverage and there is also mobile communication blind spot. In addition, in some buildings, although the phone can answer normal call but the user density, base station channel congestion and mobile phone line is difficult. In particular, the network coverage, capacity and quality of mobile communication are the key factors for operators to gain competitive advantage. Network coverage, network capacity and network quality fundamentally reflects the mobile network service level and is the theme of all mobile network optimization work. The indoor coverage system is produced under this background. According to the relevant statistics in some areas of indoor traffic in the total traffic accounted for a higher proportion. Therefore, strengthening the indoor coverage is of great significance to improve the quality of mobile communication.

KEYWORDS: mobile communication; indoor distribution coverage; system capacity
\end{abstract}

Citation: Mu JS, Su HL, Xu G, Jiang JX, et al. Design of Mobile Communication Indoor Distribution Syytem, Journal of Secure Communication and System (2017); 1(1): 47-53.

*Correspondence to: Jiaxing Jiang, Dingtai Communication Construction Engineering Co., Ltd., Shanghai, China, jjstar@qq.com.

\section{Introduction}

Indoor coverage is a successful solution for the indoor user base and for improving the mobile communication environment within the building. In recent years in all parts of the country's mobile operators have been widely used. The principle is the use of indoor antenna distribution system will move the base station signal evenly distributed in every corner of the room, so as to ensure that the indoor area has the ideal signal coverage. The construction of the indoor coverage system can improve the quality of the call in the building more comprehensively, improve the mobile phone connection rate and open up the high quality indoor mobile communication area. At the same time, the microcellular system can share the outdoor macro cellular traffic and network capacity as a whole to improve the level of mobile network services.

With the accelerating pace of mobile communication construction, the rapid increase in mobile users, large and medium cities in the outdoor area has been basically able to do seamless coverage. In order to improve network quality, improve customer satisfaction and increase traffic, indoor coverage has become the focus of network optimization. Especially with the popularity of mobile communications, mobile users in the indoor use of mobile phones is increasing, the urgent need to provide a better indoor mobile communication environment.

Indoor coverage, especially indoor coverage of wireless signals is an important part of mobile communication networks. The construction of indoor distribution system is of great significance to improve the service quality of mobile communication network. Due to the diversification and complexity of the indoor distribution system construction environment, it is necessary to seek and summarize the indoor distribution system of wireless communication network with better performance and better effect. 


\section{Overview and development of indoor distribution systems}

Indoor distribution system is the macro cell station, micro-cell station or repeater as a signal source, through the coupler, power divider and other devices to shunt through the feeder signal as much as possible to each sub-distributed installed in the building. In order to achieve the uniform distribution of indoor signals to ensure that the indoor area has the ideal signal coverage, the low antenna can be more comprehensive solution to the indoor coverage of the various problems.

\subsection{The composition of the indoor distribution system}

Indoor coverage system mainly by the signal source and distribution system and the coverage area of three parts as shown in Figure 1.1:

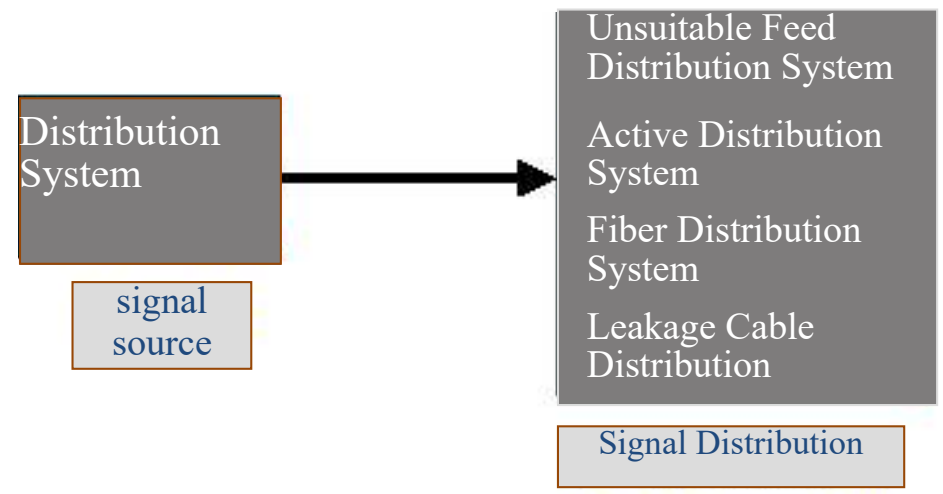

Figure 1. Block diagram of the indoor coverage system

Source: Macrocell, microcell, repeater.

Distribution system: the main RF cable, passive devices, antennas and connectors.

Coverage area: the area where the design requirements are to be achieved.

\subsection{Types and characteristics of indoor distribution systems}

Indoor distribution system can be divided into micro-cellular indoor distribution system and repeater indoor distribution system. Microphone system has the advantage of stable signal, reliable and good communication quality. The shortcomings of the construction period is longer, one-time investment and the need to pay the transmission line rental costs. The advantages of the repeater system are investment in the province, the installation is convenient and quick and the signal is weak and the blind area problem is solved quickly. The disadvantage is that it is difficult to obtain a single pure signal through the directional antenna and the voice quality of the system is relatively poor and the Interference from other base stations.

Indoor distribution systems can also be divided into passive systems and active systems. The passive system such as the base station or the microcell signal source which is shunted by passive devices such as couplers, power dividers and connectors. The signals are distributed as evenly as possible to the bottom of each coverage area of the building power antenna in order to achieve the uniform distribution of indoor signals to solve the problem of indoor signal coverage. The passive antenna system is mainly composed of coupler, combiner, power splitter, feeder and antenna. The RF signal provided by the base station or microcell is transmitted directly from the feeder to the antenna. It is a simple indoor coverage method. Passive antenna system is the basis of indoor distribution system. Equipment performance is stable, high security, easy maintenance, the signal through the power splitter, coupler and line attenuation, the arrival of the different intensity of the antenna, covering the effect is not the same.

The main components and functions of the passive antenna system are as follows:

(1) Coupler (Coupler), mainly used for trunk and branch power imbalance between the distribution.

(2) Combiner (Combiner), mainly for a number of carrier frequency or signal source and output.

(3) Splitter (Splitter), mainly used for branch connection antenna for power distribution, usually the signal energy is divided into two or more output, usually the equivalent of energy distribution. 
(4) Feeder (Coaxial), the trunk generally with $7 / 8$ ' (than $1 / 2$ ' loss of small) cable, branch generally use $1 / 2$ '(loss of relatively large) cable.

(5) Antenna (Antenna), used to radiate and receive radio waves device.

The signal of the active system through the attenuation at all levels, reach the end can be amplified by the amplifier to achieve the desired strength, to ensure coverage effect. But it builds, maintains complex, near-end and all remote devices that require power, the active device is vulnerable, and the system is less secure and stable than passive systems.

The indoor distribution system can also be divided into coaxial cable systems, fiber optic systems and leaky cable systems. Coaxial cable is the most commonly used material, stable performance, the cost is cheap but the line loss. Large coaxial cable indoor distribution system usually requires multiple trunk amplifiers for signal amplification relay. Fiber line loss is small, no trunk amplifier can also be sent to multiple areas of the signal to ensure adequate signal strength, stable and reliable performance but in the near and far to increase the photoelectric conversion equipment, the system cost is high, suitable for quality requirements of large places. Leakage cable system does not require indoor antenna, where the cable passes, the signal can leak out and complete the coverage. Leakage cable indoor distribution system is easy to install but the cost is high and the performance requirements of the cable is high while the use of less.

\subsection{The development trend of indoor distribution system}

After more than 10 years of development, the indoor coverage system has been very mature in technology. The system will have the following trends in the next few years.

(1) Digital trend of active equipment

To reduce the dry, optical and other active equipment on the $2 \mathrm{G}, 3 \mathrm{G}$ system interference, the room manufacturers have introduced digital active products through the RF signal to digitize the sampling to reduce the introduction of additional system noise and improve equipment performance. In addition, the digitization of active devices for the construction of active equipment network management system to provide the conditions to solve the operators have been plagued by the points of active equipment network management monitoring problems.

(2) Distribution system fiberization trend

In order to solve the problem of high energy loss caused by RF feeder, in response to the national construction concept of 'energy saving and emission reduction', the system has gradually begun to evolve into the fiber through the lower loss of fiber resources as the system backbone, 'High-power centralized output' design ideas into 'low-power multi-point output' ideas in order to achieve energy conservation, saving materials, saving space, cost savings purposes.

(3) Active equipment diversification trend

The digitization of active devices also creates the conditions for sharing a set of active devices for multiple sets of communication systems. The use of digital signal sampling, the gradual improvement of integrated technology as well as fiber optic cable broadband resources. There are a number of manufacturers to produce a number of sets of system signals can simultaneously amplify the multi-mode remote device in the simplified room system structure. At the same time, a number of operators to build the possibility of sharing.

\section{Indoor distribution system source access}

\subsection{Repeater for source access}

Through the repeater of the donor antenna directly from the nearby base station to extract the signal with a coupler from the nearby base station coupling part of the signal through the optical fiber to the blind area within the repeater. The repeater does not require base station equipment and transmission equipment, simple and flexible installation. Models are also rich and varied in the mobile communication is playing an increasingly important role.

(1) Through the repeater of the donor antenna directly from the nearby base station to extract the signal as shown in Figure 2-1. 


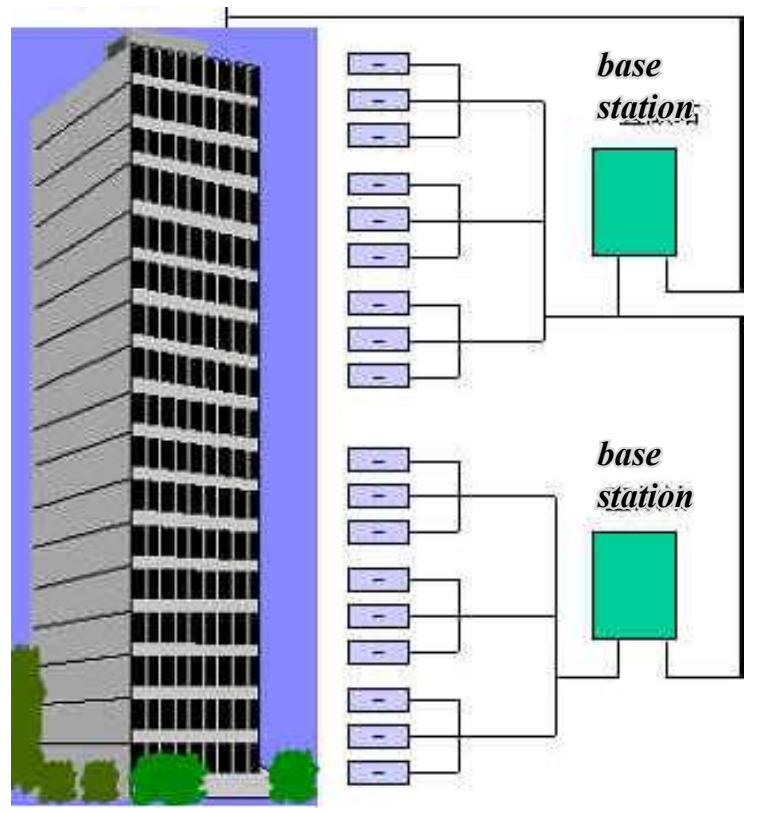

Figure 2. Extracts signals directly from nearby base stations via the donor antenna of the repeater

\subsection{Micro-cellular access for the source}

Is a micro-cellular base station as a signal distribution system of the signal source for the relatively large coverage of the traffic volume of the building is relatively high in the city to use more to solve the problem of coverage and capacity. Microphone mode call quality is better than macro cellular approach, the impact of macro-cellular wireless indicators smaller, and the role of increased capacity.

\subsection{Macro cell for source access}

Is a macro cell base station as a signal distribution system of the signal source. Macro cell for the source capacity, wide coverage, good quality, indoor distribution system is the best way to access. However the macro cell cost is high and the construction period is long.

\section{Mobile Communication Indoor Distribution System Engineering Design}

\subsection{Project Overview}

Che Tin Middle School is located in Longchuan County town of the mountain at the foot of the mountain is a beautiful campus. There is a teacher in the office area as a result of the construction of the more closed and at the lower level led to the office area inside the mobile signal weak. Currently to isolate the building within the mobile microcellular base station for the source to build a set of indoor distribution system covering the first floor of the office area. Microcell base stations can provide $30 \mathrm{~dB}$ of the source. As the coverage is small, so the introduction of the source directly through the coupler to cover the antenna. From the base station room to the coverage area of about six meters away.

\subsection{Coverage requirements}

(1) The design requirements cover the first floor of the building all the indoor and channel; taking into account the indoor environment security, indoor antenna EIRP try to control within $15 \mathrm{dBm}$; require all coverage area mobile phone receiving level of not less than $-65 \mathrm{dBm}$;

(2) Power design and propagation model diagram as shown in Figure 3; 


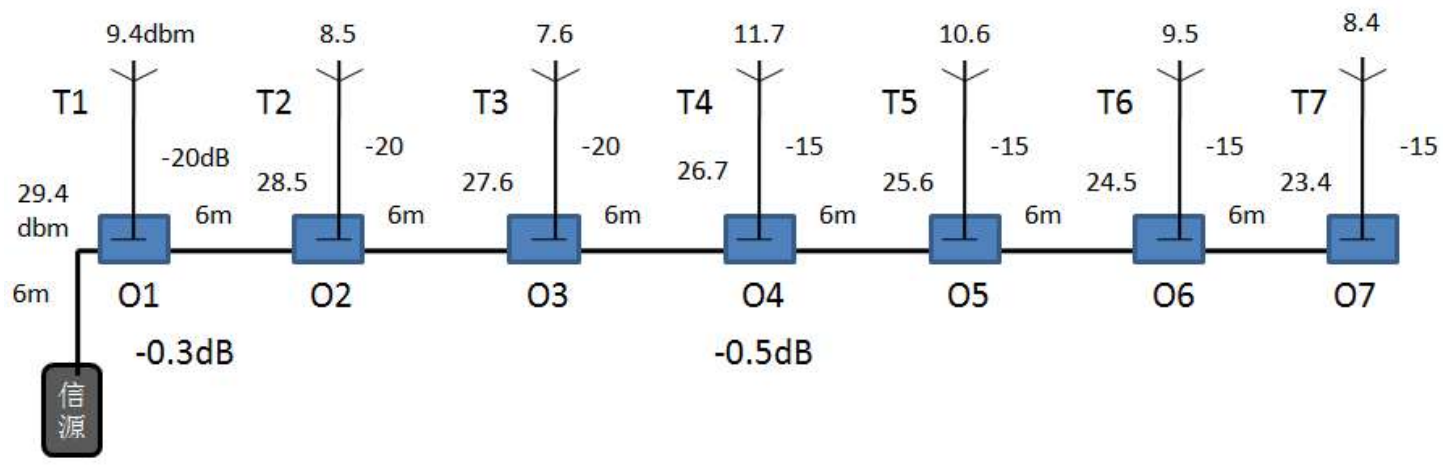

Figure 3. Propagation model diagram

\subsection{Device selection}

This project requires seven pairs of antennas, $20 \mathrm{~dB}$ coupler $3,15 \mathrm{~dB}$ coupler $4,1 / 2$ feeder 42 meters.

(1) Coupler

Table 1. Parameters of the coupler

\begin{tabular}{|c|c|c|c|c|}
\hline Product type & ${ }_{06 \mathrm{~F} 1}^{\mathrm{RC}-5 \mathrm{NK} / \mathrm{NK} / \mathrm{NK}-}$ & RC-5NK/NK/NK-10F1 & $\mathrm{RC}-5 \mathrm{NK} / \mathrm{NK} / \mathrm{NK}-15 \mathrm{~F} 1$ & $\begin{array}{l}{ }_{20} \text { RC-5NK/NK/NK- } \\
20 \mathrm{r} 1\end{array}$ \\
\hline $\begin{array}{l}\text { Operating } \\
\text { Frequency (MHz) }\end{array}$ & \multicolumn{4}{|l|}{$800 \sim 2500$} \\
\hline $\begin{array}{l}\text { Input } \\
\text { resistance }(\Omega)\end{array}$ & \multicolumn{4}{|l|}{50} \\
\hline Enter the standing wave ratio & \multicolumn{4}{|l|}{$\leq 1.3$} \\
\hline $\begin{array}{l}\text { Degree of } \\
\text { orientation }(\mathrm{dB})\end{array}$ & $15 \mathrm{~dB}$ & $15 \mathrm{~dB}$ & $15 \mathrm{~dB}$ & $15 \mathrm{~dB}$ \\
\hline Coupling degree & $6 \mathrm{~dB}$ & $10 \mathrm{~dB}$ & $15 \mathrm{~dB}$ & $20 \mathrm{~dB}$ \\
\hline $\begin{array}{l}\text { Through the } \\
\text { loss }(\mathrm{dB})\end{array}$ & $\leq 1.5$ & $\leq 0.71$ & $\leq 0.49$ & $\leq 0.3$ \\
\hline Through power (W) & \multicolumn{4}{|l|}{100} \\
\hline Connecto & \multicolumn{4}{|l|}{$\mathrm{N}-\mathrm{K}$} \\
\hline Weight (kg) & \multicolumn{4}{|l|}{0.48} \\
\hline Volume (mm) & \multicolumn{4}{|l|}{$141 \times 58 \times 24$} \\
\hline Ambient temperature & \multicolumn{4}{|l|}{$-35^{\circ} \mathrm{C} \sim 75^{\circ} \mathrm{C}$} \\
\hline Relative humidity & \multicolumn{4}{|l|}{$\leq 95 \%$} \\
\hline
\end{tabular}

(2) Antenna

\begin{tabular}{c|c}
\hline Frequency range & $824-960 \mathrm{MHz}, 1710 \sim 2500 \mathrm{MHz}$ \\
\hline Power capacity & $50 \mathrm{~W}$ \\
\hline Gain & $2.1 \mathrm{dBi}$ \\
\hline Horizontal half power lobe width & $360^{\circ}$ \\
\hline Vertical face half power lobe width & $180^{\circ}$ \\
\hline Standing wave ratio & $\leq 1.5$ \\
\hline
\end{tabular}




\begin{tabular}{c|c}
\hline Polarization mode & Horizontal \\
\hline Resistance & $50 \Omega$ \\
\hline Feed type & $\mathrm{N}-\mathrm{K}$ \\
\hline Volume weight & $\varphi 200 ; \mathrm{H} 78 \mathrm{~mm} ; \mathrm{W} 0.5 \mathrm{Kg}$ \\
\hline Radiation unit material & circuit board \\
\hline Radome material & Nylon \\
\hline
\end{tabular}

(3) Feeder

In order to reduce the loss of the signal in the feeder on the system using $1 / 2$ hard feed line loss of $1 \mathrm{~dB} / 10$ meters.

\subsection{Indoor coverage field strength verification}

For the indoor coverage system, the free space propagation loss of radio waves is used. The formula for calculating the free space propagation loss is shown in Equation 4-1.

(4) $/ 20 \lg (4 \pi / C)+20 \lg (\mathrm{f})+20 \lg (\mathrm{d})(4-1)$

Where: $\mathrm{d}$ is the transmission distance, in $\mathrm{m}$; $\mathrm{f}$ is the radio frequency, in $\mathrm{Hz}(\mathrm{GSM} 900 \mathrm{MHz})$; $\mathrm{C}$ is the speed of light, take $300000000 \mathrm{~m} / \mathrm{s}$.

Table 2. Average barrier loss of building materials and structures for general buildings

\begin{tabular}{c|c|c|c|c}
\hline Material Type & Concrete Wall & Concrete Floor & Ceiling & Metal Partition \\
\hline Loss & $10 \sim 15 \mathrm{~dB}$ & $15 \sim 20 \mathrm{~dB}$ & $1 \sim 8 \mathrm{~dB}$ & $5 \mathrm{~dB}$ \\
\hline \multirow{2}{*}{ Material type } & Reinforced concrete wall & Ordinary wooden door & Elevator & Corner \\
& & & & \\
\hline Loss & $20 \mathrm{~dB}$ & $4 \mathrm{~dB}$ & $25 \mathrm{~dB}$ & $3 \mathrm{~dB}$ \\
\hline
\end{tabular}

In the $\mathrm{T} 3$ to its coverage area of the longest distance of not more than ten meters, according to ten meters of its free space propagation loss:

$\operatorname{Ls}(\mathrm{dB})=20 \lg (4 \pi \mathrm{df} / \mathrm{C})=20 \lg (4 \times \pi \times 10 \times 3)=51.5 \mathrm{~dB}$

Plus the total loss of a wall;

$51.5 \mathrm{~dB}+15 \mathrm{~dB}=66.5 \mathrm{~dB}$

Antenna's transmit power is $9.7 \mathrm{dBm}$; indoor mobile phone field strength is:

$9.7 \mathrm{dBm}-66.5 \mathrm{~dB}=-56.8 \mathrm{dBm}$

$-56.8 \mathrm{dBm}>=-65 \mathrm{dBm}$ so meet the requirements.

\section{Construction Specifications and Requirements}

\subsection{Installation of the antenna}

(1) Installation of the antenna reference antenna point and cable routing map, installed in the decoration of the ceiling or ceiling, to ensure that the antenna level and beautiful, flat and does not destroy the overall indoor environment.

(2) Antenna according to the design of the logo in the label, easy to maintain in the future.

(3) Note that the height of all feeder lines is not lower than the existing minimum objects such as fire detectors.

\subsection{Laying of the feeder}

(1) Do not damage the insulation layer when laying the feed cable and feeder; the cable must be laid for easy maintenance and consider the need for future expansion. Care should be careful not to pull the cable too tight, not cross, distorted, cracked the situation. The bending radius shall conform to the technical standard of the feeder and shall also take into account the installation location of the relevant device. 
(2) When laying cables, each cable shall be clearly numbered for inspection and connection. The cable label shall be affixed to the obvious ends of the cable and shall not be easily disengaged.

(3) All the feeders are protected with PVC pipe, the main feeder must be a good fixed line wells, cloth placed in the ceiling feeder fixed in the ceiling on the dragon frame. Cable laying process should be used near the cable, feeder seat or feeder clip fixed, ceiling cable inside the keel fixed, no ceiling should be fixed on the wall.

(4) Before the feeder line enters the room from the feeder port, it is required to have a 'drip bend' or a slanting line to prevent rainwater from penetrating into the room along the feeder line. Casing water). Feeder inlet and outlet wall of the application of waterproof, flame retardant materials for sealing. External feeder connections, feeder grounding points must be waterproof seal.

(5) Tube requirements: All pipelines are arranged in a neat and beautiful manner, as far as possible against the wall, and fixed with a wire or feeder clamp as required. Use a cornering or bellows connection such as a corrugated pipe.

\subsection{Feeder and device installation}

(1) The feeder connector must be firmly installed, the correct use of the first tool to do the head, in strict accordance with the steps on the instructions, the connector cannot be loose, feeder core and the skin cannot have burrs, tighten the lower part of the screw to the upper part, To ensure good contact, to keep the standing wave ratio $<1.5$ or less, and outdoor or wet areas of the joints do waterproof sealing treatment. Feeder connector and host / extension, antenna, coupler, power splitter connection, the connection must be reliable, the connector into the wire smooth, from the feeder connector must be kept $50 \mathrm{~mm}$ long feeder straight out before turning.

(2) Feeder is too long to be cut off cannot be around the device, try to shorten the feeder length to reduce the loss. To ensure that the amount of feeder length and then cut off the feeder, so that a successful, shorter connection to the amount of good to do later, not because of easy to connect and hit the sharp bend.

\section{Conclusions}

This paper introduces the indoor distribution system construction necessity, the type and characteristics of the system from the indoor distribution system of mobile network and its background. The construction of indoor distribution system is of great significance to improve service level and quality, improve the image of operators and increase call revenue. Therefore, to improve the mobile communication indoor coverage problem has multiple meanings. It expands the coverage area of the signal, reduce the blind area and increase the traffic. On the other hand, it improves the connection rate and switching success rate. Furthermore, it can improves the image of telecommunications companies, network competitiveness and to provide users with better service. At the same time due to the indoor distribution system construction environment diversity and complexity to achieve good results in low cost need to continue to explore and summarize in practice.

\section{References}

1. Lu Jianxian. Mobile communication distribution system theory and engineering design [M]. Beijing: Mechanical Industry Publishing, 2003.

2. Zhang Chuanfu. CDMA mobile communication network planning and design and optimization [M]. Beijing: People's Posts and Telecommunications Press, 2006.

3. Wei Hong. Mobile base station equipment and maintenance [M]. Beijing: People's Posts and Telecommunications Press, 2009.

4. Dai Yuan. TD-LTE wireless network planning and design [M]. Beijing: People's Posts and Telecommunications Press, 2012.

5. Zhang Ping. CDMA mobile communication system [M]. Beijing: People's Posts and Telecommunications Press, 2002.

6. Zeng Qingzhu. Mobile Communications [M]. Beijing: Polytechnic University Press, 2009.

7. Han Binjie. GSM principle and its network optimization [M]. Beijing: Mechanical Industry Press, 2009.

8. Qi YuSheng. Modern mobile communication system [M]. Beijing: People's Posts and Telecommunications Press, 2009. 